\title{
Active and Reactive Power Control of Wind Turbine based on Doubly Fed Induction Generator using Adaptive Sliding Mode Approach
}

\author{
Othmane Zamzoum ${ }^{1}$, Youness El Mourabit ${ }^{2}$, Mustapha Errouha $^{3}$, Aziz Derouich $^{4}$, Abdelaziz El Ghzizal $^{5}$ \\ Université Sidi Mohamed Ben Abdellah, Ecole Superieure de Technologie de Fès, Fez, Morocco
}

\begin{abstract}
In this work, a robust Adaptive sliding mode controller (ASMC) is proposed to improve the dynamic performance of the Doubly Fed Induction generator (DFIG) based wind system under variable wind speed conditions. Firstly, the dynamic modeling of the main components of the system is performed. Thereafter, the ASMC is designed to control the active and reactive powers of the machine stator. The structure of these controllers was improved by adding two integral terms. Their sliding gains are determined using Lyapunov stability theorem to make them automatically adjusted in order to tackle the external disturbances. Maximum Power Point Tracking (MPPT) strategy was also applied to enhance the power system efficiency. Then, a comparison study with the Field Oriented Control (FOC) based on conventional PI control was conducted to assess the robustness of this technique under the DFIG parameters variations. Finally, a computer simulation was achieved in MATLAB/SIMULINK environment using 2MW wind system model. Satisfactory performances of the proposed strategy were clearly confirmed under variable operating conditions.
\end{abstract}

Keywords-Wind turbine; DFIG; OP-MPPT; ASMC; adaptive sliding gains

\section{INTRODUCTION}

Undoubtedly, the over consumption of fossil fuels like oil, coal and natural gas can cause a serious environmental problems such as temperature increases, acid rain and air pollution which have a negative impact on humans, animals and plants [1]. Furthermore, these sources are limited and they have a fast rate depletion. For these reasons, the governments are committed to practices and policies that promote clean and renewable energies [2].

Wind energy is magnificently shining in the previous few years among a diversity of renewable energy sources for several reasons. It is renewable, unlimited and cost-effective that leads to an effective energy production [3]. Thanks to all these benefits, the wind installed capacity raised significantly from $94 \mathrm{GW}$ to $539 \mathrm{GW}$ worldwide in the last decade and this growth will continue surprising. It is expected that $1600 \mathrm{GW}$ can be reached by the end of 2030 [4].

The most popular technology in wind turbine industry is the variable speed wind system for several reasons [5]. The tip speed ratio should be kept constant in order to extract the greater amount of wind energy. This can be acquired only if the rotor speed and wind velocity vary simultaneously. Hence, the power coefficient can be improved regardless of the changing wind speed. Moreover, the variable speed operation allows reducing component fatigue and power fluctuations. This technology is possible with either induction machines or synchronous ones by using the power converters as interface between the machine and the grid [6].

The DFIG have been widely employed in large scale variable speed wind system [7]. According to the 2016 wind energy annual report of the European Commission's Joint Research Centre (JRC) [8], The DFIG configuration dominates the wind turbine market with $68 \%$ of the onshore installed capacity worldwide. The wind system topology based on this kind of generator has numerous advantages. It can operate in both supersynchonous or subsynchronous mode. It offers controlling the whole active and reactive powers interchanged with the grid. This is done by a back to back converter rated only at $30 \%$ of generator nominal power which can reduce the weight, the cost and power losses in the converter [9].

Several works in the literature have revealed an increasing attention in control of the DFIG based wind turbines in order to operate reliably and safely. The most dominating strategy is the Field Oriented Control (FOC) based on PI controllers [10]. It is founded on decoupling the $\mathrm{d}-\mathrm{q}$ components of the rotor currents to control independently the active and reactive powers, which can yield satisfactory dynamic performances [11]. However, it needs accurate machine parameters and remains sensitive to the external disturbances and the drive parameter variations [12]. Another widely used technique is the direct torque control (DTC) [13]. This technique can deal with the drive uncertainties but its main drawback is the torque and the flux ripples during low speed operating mode [14]. To handle the nonlinearities in the DFIG model, these control methods are upgraded using artificial intelligence algorithms such as fuzzy logic control (FLC) and neural network control (NNC) [15]. Nevertheless, they require more calculation time and need experience and good skills to adjust their parameters [16]. The Sliding Mode Control (SMC) has demonstrated a strong robustness against the nonlinearities and the complexity of the wind system [17]. However, the high frequency oscillations of the state variable trajectories caused by the chattering phenomena remains its most serious problem. It can be overcome by replacing the sign function with a smoothing continuous one. The adaptive sliding controller gains are established to more enhance the SMC performances in wide external disturbances range [18]. 
To improve the SMC efficiency, the controlled active power should track an optimal reference value. This can be achieved by using Maximum Power Point Tracking (MPPT) technique, which is applied when the wind speed is below its rated value [17]. A variety of MPPT techniques were presented in [19], like optimal power control (OPC), power signal feedback technique (PSF), perturbation and observation algorithm (P\&O) and the Tip Speed Ratio method (TSR). In this paper, the optimal power reference is generated using MPPT-OPC. This technique is widely employed in literature for slow varying wind velocity due to its simplicity and effectiveness without necessity of wind speed measurements. It requires only the wind system power curves to adjust the rotor speed in order to keep the power coefficient at its optimal value.

The general structure of variable speed wind system based on DFIG is represented in Fig. 1. The wind energy is harvested by a three blades turbine and converted to mechanical one. The slow rotational speed is increased using a gearbox allowing in its output a high speed that needs the DFIG to generate electricity. The stator of the wound rotor induction generator is directly coupled to the electrical grid while the slip rings of its rotor windings are attached thereto via partially rated power electronic converters. The Rotor Side Converter (RSC) allows regulating the stator active and reactive powers. The reference of the active one is determined using MPPT strategy. The Grid side converter controls the active and reactive powers exchanged between the machine rotor and the grid [20].

In the present paper, a robust Adaptive Sliding Mode Controller (ASMC) is proposed to control the powers flow of the wind turbine based on DFIG under fluctuating wind speed. The switching surfaces of the state power errors are described by two integral functions and the Lyapunov stability theorem is adopted to determine the controllers adaptive gains. Furthermore, a comparative study between the SMC and the field-oriented control based on PI controllers is conducted to prove the effectiveness of the suggested strategy under machine parameters uncertainties.

The remainder of this work is structured as follows: in Section 2, the dynamic modeling of the DFIG based WECS main parts is introduced. Section 3 presents the synthesis of the different techniques adopted for wind turbine control. Noticed that only the RSC control is considered in this paper. Section 4 details the steps to achieve an optimal design of the sliding mode controller. Finally, the obtained results from the implementation of the wind system model using MATLAB/SIMULINK environment are discussed and interpreted.

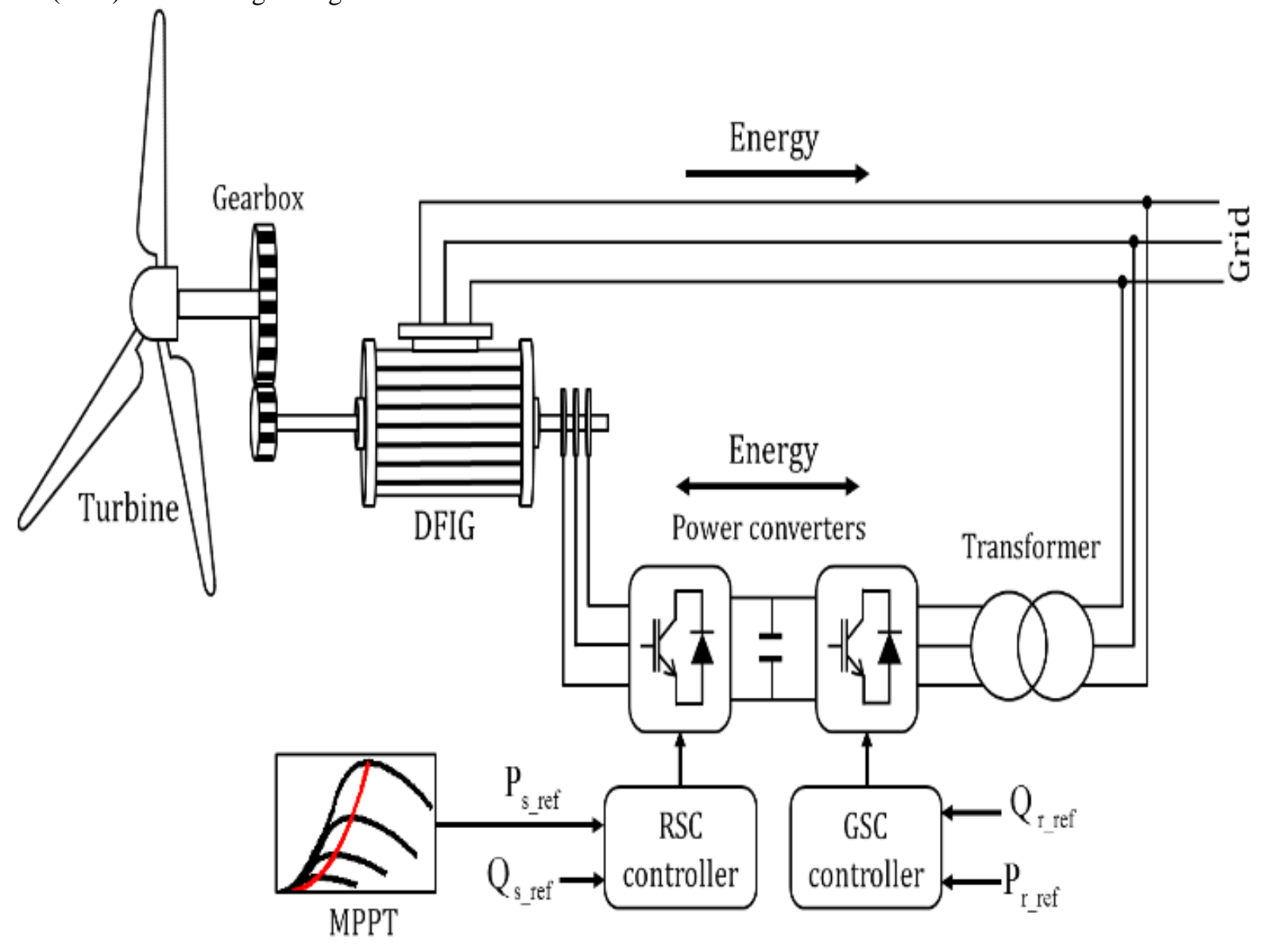

Fig. 1. Architecture of DFIG based wind System. 


\section{VARIABLE SPEED WIND SySTEM MODELING}

\section{A. Turbine and Gear-Box Modeling}

The aerodynamic power converted by the turbine $\left(\mathrm{P}_{\mathrm{aer}}\right)$ and the torque $\left(\mathrm{C}_{\mathrm{aer}}\right)$ developed on its shaft are defined by [21]:

$$
\begin{aligned}
& P_{a e r}=\frac{1}{2} C_{p}(\lambda, \beta) \rho \pi R_{t}^{2} v_{w}{ }^{3} \\
& C_{a e r}=\frac{P_{a e r}}{\Omega_{t u r}}
\end{aligned}
$$

where $\rho$ and $R_{t}$ are respectively the air density and the rotor radius respectively, $\mathrm{v}_{\mathrm{w}}$ is the wind speed and $\Omega_{\text {tur }}$ is the angular velocity of the turbine shaft.

The power coefficient $C_{p}$ represents the efficiency with which blades can capture the kinetic energy of the wind. It is a nonlinear function of the tip speed ratio (TSR) $\lambda$ and the pitch angle of the blades $\beta$ as depicted in Fig. 2. The first parameter is proportional to the ratio between the turbine and the wind velocity. $C_{p}$ and $\lambda$ are expressed respectively by (3) and (4) [22].

$$
\left\{\begin{array}{c}
C_{p}(\lambda, \beta)=0.5872\left(\frac{116}{\lambda_{i}}-0.4 \beta-5\right) e^{-\frac{21}{\lambda_{i}}}+0.0085 \lambda \\
\frac{1}{\lambda_{i}}=\frac{1}{\lambda+0.08 \beta}-\frac{0.035}{\beta^{3}+1}
\end{array}\right.
$$

$\lambda=\frac{\Omega_{t u r} \cdot R_{t}}{v_{w}}$

In order to keep the speed of the generator shaft in the wanted range, the turbine and generator shafts are coupled via a gearbox. The speed and the torque generator from the gearbox are given by the following expressions [23]:

$C_{g}=\frac{1}{G} C_{a e r}$

$\Omega_{\text {tur }}=\frac{1}{G} \Omega_{m e c}$

where $C_{g}$ is the electrical machine torque, $\Omega_{\text {mec }}$ is the speed of the machine rotor shaft and $\mathrm{G}$ refers to the gearbox ratio.

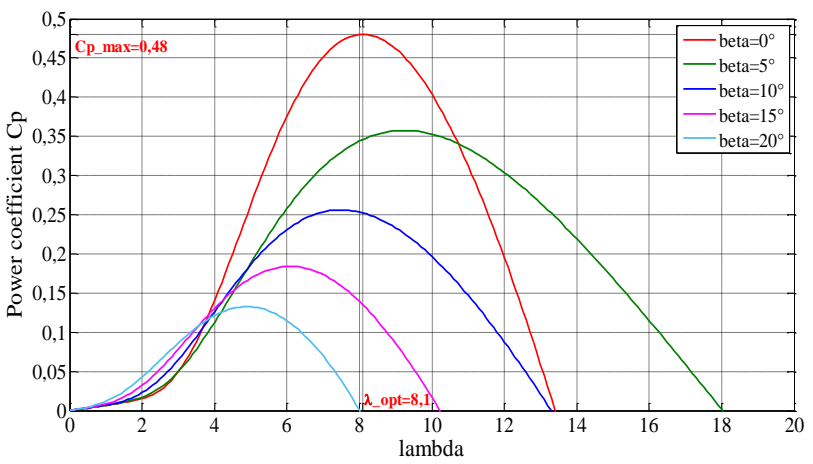

Fig. 2. $C_{p}$ in Terms of $\beta$ and $\lambda$.

\section{B. DFIG Dynamic Model}

In the objective to define the DFIG control strategy, its dynamic mathematical model is required. Using the PARK transformation, the voltages and the fluxes equations of the generator in the synchronous reference frame $(\mathrm{d}-\mathrm{q})$ are described by the following equations [24]:

$$
\begin{aligned}
& \left\{\begin{array}{l}
v_{s d}=R_{s} i_{s d}+\frac{d \Phi_{s d}}{d t}-\omega_{g} \Phi_{s q} \\
v_{s q}=R_{s} i_{s q}+\frac{d \Phi_{s q}}{d t}+\omega_{g} \Phi_{s d} \\
v_{r d}=R_{r} i_{r d}+\frac{d \Phi_{r d}}{d t}-\omega_{r} \Phi_{r q} \\
v_{r q}=R_{r} i_{r q}+\frac{d \Phi_{r q}}{d t}+\omega_{r} \Phi_{r d}
\end{array}\right. \\
& \left\{\begin{array}{l}
\Phi_{s d}=L_{s} i_{s d}+M i_{r d} \\
\Phi_{s q}=L_{s} i_{s q}+M i_{r q} \\
\Phi_{r d}=L_{r} i_{r d}+M i_{s d} \\
\Phi_{r q}=L_{r} i_{r q}+M i_{s q}
\end{array}\right.
\end{aligned}
$$

where $\Phi_{\mathrm{rd}, \mathrm{q}}$ and $\Phi_{\mathrm{sd}, \mathrm{q}}$ are the rotor and the stator fluxes respectively, $\mathrm{V}_{\mathrm{rd}, \mathrm{q}}$ and $\mathrm{V}_{\mathrm{sd}, \mathrm{q}}$ are the rotor and stator voltages, $\mathrm{R}_{\mathrm{r}}$ and $R_{s}$ are the rotor and stator resistances, $L_{r}, L_{s}$ and $M$ are the rotor, stator and magnetizing inductances, $\sigma$ is the leakage factor, $\omega_{\mathrm{m}}$ and $\omega_{\mathrm{g}}$ are the angular frequencies of the rotor shaft and the stator flux.

The link between the electrical and mechanical part of the generator is presented by the electromagnetic torque. It can be written in terms of fluxes as [25]:

$$
C_{e m}=\frac{3}{2} p \frac{M}{\sigma L_{s} L_{r}}\left(\Phi_{s q} \Phi_{r d}-\Phi_{s d} \Phi_{r q}\right)
$$

The mechanical equation of the generator can be written as:

$J \frac{d \Omega_{m e c}}{d t}=C_{g}-C_{e m}-f_{v} \Omega_{m e c}$

where $f_{v}$ is the viscous friction and $J$ is the wind turbine inertia.

The stator active and reactive powers are obtained by (11) and (12) [26]:

$$
\begin{aligned}
& P_{s}=\frac{3}{2}\left(V_{s d} I_{s d}+V_{s q} I_{s q}\right) \\
& Q_{s}=\frac{3}{2}\left(V_{s q} I_{s d}-V_{s d} I_{s q}\right)
\end{aligned}
$$

\section{Voltage Converter Modeling}

The power electronic converter based on Insulated Gate Bipolar Transistors (IGBT) is used to interface the rotor of the DFIG and the grid. It can be modeled by the following matrix form [27]: 


$$
\left[\begin{array}{l}
V_{a r} \\
V_{b r} \\
V_{c r}
\end{array}\right]=\frac{V_{D}}{3}\left[\begin{array}{ccc}
2 & -1 & -1 \\
-1 & 2 & -1 \\
-1 & -1 & 2
\end{array}\right]\left[\begin{array}{l}
S_{a} \\
S_{b} \\
S_{c}
\end{array}\right]
$$

where $\mathrm{V}_{\mathrm{ar}}, \mathrm{V}_{\mathrm{br}}$ and $\mathrm{V}_{\mathrm{cr}}$ are the output rotor voltages, $\mathrm{V}_{\mathrm{D}}$ is DC link voltage and $S_{a}, S_{b}$, and $S_{c}$ are the IGBT control signals.

\section{CONTROL STRATEGIES FOR THE WECS}

\section{A. Maximum Power Point Tracking Technique}

To increase the captured energy and to enhance the energy conversion efficiency, many MPPT control schemes have been developed. In this paper, the interest is given to one of the most commonly used MPPT strategy that is the Optimal Power-MPPT (OP-MPPT). With this strategy, this objective can be achieved in the second operating zone when the wind speed is below its nominal value and without wind speed measurements [28, 29].

As illustrated in Fig. 3, the optimal wind power should be extracted for a specific turbine velocity at a given wind speed. Consequently, the wind system should work in variable speed mode.

The OP-MPPT is based on regulation of the turbine rotational speed in order to keep the TSR at its optimal value $\lambda_{\text {opt }}$. As shown in Fig. 2, $\lambda_{\text {opt }}=8,1$ allows us to reach the maximum point of the power coefficient $\mathrm{C}_{\mathrm{p}_{-} \max }=0,48$ which corresponds to the maximal mechanical power. In this zone, the pitch angle $\beta$ is maintained constant at zero.

The expression of the mechanical power in terms of rotational speed of the turbine, $\lambda_{\text {opt }}$ and $\mathrm{C}_{\mathrm{p}_{-} \max }$ is given by the following equation:

$$
P_{\text {aer_ref }}=\frac{1}{2 \lambda_{\text {opt }}^{3}} C_{p_{-} \max } \rho \pi R^{5} \Omega_{t u r}^{3}
$$

During the control technique, the controlled magnitudes are the active and reactive powers of the generator stator. Thus, the stator power reference can be determined by subtracting the estimated rotor power $\mathrm{P}_{\mathrm{r} \_ \text {est }}$ from $\mathrm{P}_{\text {aer_ref }}$;

$P_{s_{-} \text {ref }}=P_{\text {aer_ref }}-P_{r}$

The two last expressions lead to the block diagram represented in Fig. 4.

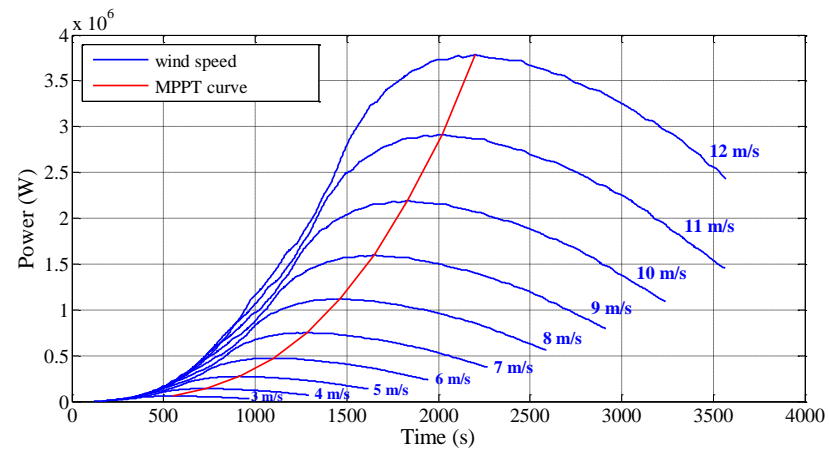

Fig. 3. Optimal Power Curve for Different Wind Speeds.

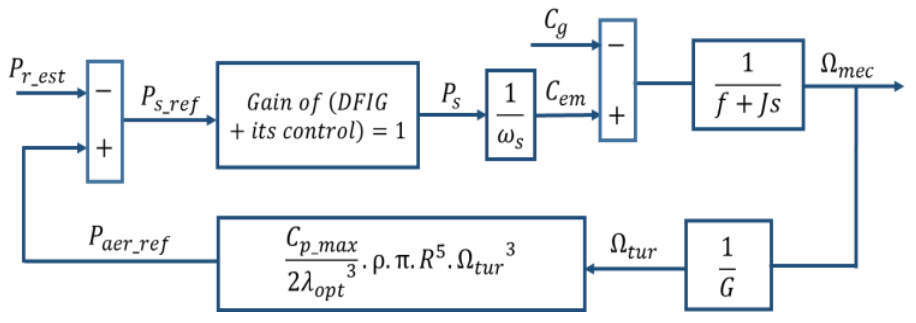

Fig. 4. OP-MPPT Control Structure.

\section{B. Stator Active and Reactive Powers Control}

1) Stator field oriented technique: In order to separately control the stator active and reactive powers of the wind turbine generator, the stator flux linkage is aligned with the direct axis of PARK reference frame [22, 30]. There are other alignment possibilities in the literature such as using the stator voltage vector or rotor flux linkage, but using the stator flux vector still the most commonly used for control of the DFIG applications. This technique separates the rotor current vector into two components: the direct one is related to the reactive power and the quadrature one allows controlling the active power.

This technique allows deriving the relationship between the rotor and stator currents by simplifying the stator flux equations as expressed by the following equations [31]:

$I_{s d}=\frac{\Phi_{s d}}{L_{s}}-\frac{M}{L_{s}} I_{r d}$

$I_{s q}=-\frac{M}{L_{s}} I_{r q}$

The rotor flux can be expressed in terms of rotor currents by replacing the above equations into (8):

$$
\begin{aligned}
& \Phi_{r d}=\left(L_{r}-\frac{M^{2}}{L_{s}}\right) i_{r d}+\frac{M}{L_{s}} \Phi_{s d} \\
& \Phi_{r q}=\left(L_{r}-\frac{M^{2}}{L_{s}}\right) i_{r q}
\end{aligned}
$$

By substituting the above equations into (7), the rotor voltage dynamics can be established in terms of rotor currents:

$V_{r d}=R_{r} I_{r d}+\left(L_{r}-\frac{M^{2}}{L_{s}}\right) \frac{d I_{r d}}{d t}-\left(L_{r}-\frac{M^{2}}{L_{s}}\right)\left(\omega_{s}-\omega_{m}\right) I_{r q}+\frac{M}{L_{s}} \frac{d \Phi_{s d}}{d t}$

$V_{r q}=R_{r} I_{r q}+\left(L_{r}-\frac{M^{2}}{L_{s}}\right) \frac{d I_{r q}}{d t}-\left(L_{r}-\frac{M^{2}}{L_{s}}\right)\left(\omega_{s}-\omega_{m}\right) I_{r d}+\frac{M}{L_{s}}\left(\omega_{s}-\omega_{m}\right) \Phi_{s d}$

In order to express the rotor voltages in terms of stator active and reactive powers, the relationship between the rotor currents and stator active and reactive powers should be estimated. Taking into account that the voltage drop in the stator resistance can be neglected for the large-scale wind 
turbine, the expressions of stator powers can be simplified as expressed in the following equations [27]:

$P_{s}=-\frac{3}{2} V_{s} \frac{M}{L_{s}} I_{r q}$

$Q_{s}=\frac{3}{2} \frac{\Phi s d}{L_{s}} V_{s}-\frac{3}{2} \frac{M}{L_{s}} V_{s} I_{r d}$

Finally, the rotor voltage equations can be rewritten to determine stator active and reactive powers dynamic as follow:

$$
\begin{aligned}
& \dot{P}_{s}=-\frac{R_{r}}{\sigma L_{r}} P_{s}-\left(\omega_{\lambda s}-\omega_{m}\right) Q_{s}-\frac{3}{2} \frac{M}{\sigma L_{s} L_{r}}\left|\vec{V}_{s}\right| u_{r q}+\frac{3}{2}\left|\vec{V}_{s}\right|\left(\frac{1}{L_{s}}+\frac{M^{2}}{\sigma L_{r} L_{s}^{2}}\right)\left(\omega_{\lambda s}-\omega_{m}\right) \lambda_{s d} \\
& \dot{Q}_{s}=\left(\omega_{\lambda s}-\omega_{m}\right) P_{s}-\frac{R_{r}}{\sigma L_{r}} Q_{s}-\frac{3}{2} \frac{M}{\sigma L_{s} L_{r}}\left|\vec{V}_{s}\right| u_{r d}+\frac{3}{2} \frac{R_{r}}{\sigma L_{s} L_{r}}\left|\vec{V}_{s}\right| \lambda_{s d}+\frac{3}{2}\left|\vec{V}_{s}\right|\left(\frac{1}{L_{s}}+\frac{M^{2}}{\sigma L_{r} L_{s}^{2}}\right) \frac{d \lambda_{s d}}{d t}
\end{aligned}
$$

2) Adaptive sliding mode approach: Adaptive sliding mode control (ASMC) is a very powerful technique developed to control different classes of nonlinear systems. This control strategy is adopted to overcome the external disturbances and modeling uncertainties of the regulated process as well as its simplicity of implementation and satisfactory dynamical response [32]. The ASMC consists of forcing a state variable trajectory to converge to stable surfaces and sliding along them until reaching a desired equilibrium point. The ASMC performance is improved by updating the adaptive gain. The derivation of this parameter is performed by Lyapunov stability theorem with the aim of ensuring the stability and finding the optimal state variable trajectory [33]. In this paper, this technique is used to calculate the rotor voltage references in order to keep the active and reactive powers at their optimal values. The design of these controllers consists of three steps:

- Sliding surface design

- Control signals calculation

- Stability analysis

3) Sliding surface design: To determine the sliding surface for a nth order system, the general equation proposed in [34] is presented by:

$S=\left(\frac{d}{d t}+\lambda\right)^{n-1} \tilde{x}$

where $\tilde{x}=x_{r e f}-x$ is the state variable error and $\lambda$ denotes a positive coefficient.

As the system described by (24) and (25) is a first order system $n=1$, the active and reactive power errors are taken as sliding surfaces. An integral term is added in order to improve the control performance in terms of static error elimination. The integral sliding surface vectors are expressed by:

$S_{P}=e_{P}+c_{1} \int_{0}^{t} e_{P} d t$
$S_{Q}=e_{Q}+c_{2} \int_{0}^{t} e_{Q} d t$

where $\mathrm{C}_{1}$ and $\mathrm{C}_{2}$ are positive coefficients.

4) Control signals calculation: In the ASMC of stator powers, the state variables are active and reactive power errors $\mathrm{e}_{\mathrm{P}}$ and $\mathrm{e}_{\mathrm{Q}}$ and the control outputs are the rotor voltage components in d-q reference frame. Thus:

$$
\begin{aligned}
& x=\left[\begin{array}{ll}
e_{P} & e_{Q}
\end{array}\right]^{T}=\left[\begin{array}{ll}
P_{s}^{*}-P_{s} & Q_{s}^{*}-Q_{s}
\end{array}\right]^{T} \\
& u=\left[\begin{array}{ll}
u_{r d} & u_{r q}
\end{array}\right]^{T}
\end{aligned}
$$

where Ps* and Qs* are the stator power references.

The dynamic of stator power errors can be described in the state space form as:

$\left[\begin{array}{c}\dot{e}_{P} \\ \dot{e}_{Q}\end{array}\right]=\left[\begin{array}{cc}A_{11} & A_{12} \\ A_{21} & A_{22}\end{array}\right]\left[\begin{array}{l}e_{P} \\ e_{Q}\end{array}\right]+\left[\begin{array}{cc}0 & B_{1} \\ B_{2} & 0\end{array}\right]\left[\begin{array}{l}u_{r d} \\ u_{r q}\end{array}\right]+\left[\begin{array}{l}E_{1} \\ E_{2}\end{array}\right]$

\[ A_{11}=A_{22}=-\frac{R_{r}}{\sigma L_{r}}, A_{12}=-A_{21}=-\left(\omega_{\lambda s}-\omega_{m}\right) \text {, } \]
where:

$B_{1}=B_{2}=\frac{3}{2} \frac{M}{\sigma L_{s} L_{r}}\left|\vec{V}_{s}\right|$

$E_{1}=-\frac{3}{2}\left|\vec{V}_{s}\right|\left(\frac{1}{L_{s}}+\frac{M^{2}}{\sigma L_{r} L_{s}^{2}}\right)\left(\omega_{\lambda s}-\omega_{m}\right) \lambda_{s d}+\frac{R_{r}}{\sigma L_{r}} P_{s}^{*}+\left(\omega_{\lambda s}-\omega_{m}\right) Q_{s}^{*}+\dot{P}_{s}^{*}$

$E_{2}=-\frac{3}{2} \frac{R_{r}}{\sigma L_{s} L_{r}}\left|\vec{V}_{s}\right| \lambda_{s d}-\frac{3}{2}\left|\vec{V}_{s}\right|\left(\frac{1}{L_{s}}+\frac{M^{2}}{\sigma L_{r} L_{s}^{2}}\right) \frac{d \lambda_{s d}}{d t}-\left(\omega_{\lambda s}-\omega_{m}\right) P_{s}^{*}+\frac{R_{r}}{\sigma L_{r}} Q_{s}^{*}+\dot{Q}_{s}^{*}$

The reaching law, expressed by (32) and (33), is designed to force the system trajectory around the sliding surface.

$\dot{S}_{P}=-\varepsilon_{1} \operatorname{sgn}\left(S_{P}\right)$

$\dot{S}_{Q}=-\varepsilon_{2} \operatorname{sgn}\left(S_{Q}\right)$

where $\varepsilon_{1}$ and $\varepsilon_{2}$ are the switching gains, which will be estimated later using Lyapunov stability theorem.

To reduce the chattering phenomenon caused by sgn function (high switching frequency) and to have good commutation around the defined surfaces, the signum function can be substituted by a smoothing continuous function expressed by the following equation:

$\tanh (S)=\frac{e^{2 S}-1}{e^{2 S}+1}$

Finally, the adaptive sliding mode control law can be deduced from (31), (35) and (36) and its general structure is represented in Fig. 5.

$u_{r d}=-\frac{1}{B_{2}}\left[A_{21} e_{P}+\left(c_{2}+A_{22}\right) e_{Q}+\varepsilon_{2} \operatorname{sgn}\left(S_{Q}\right)\right]$ 
$u_{r q}=-\frac{1}{B_{1}}\left[\left(c_{1}+A_{11}\right) e_{P}+A_{12} e_{Q}+\varepsilon_{1} \operatorname{sgn}\left(S_{P}\right)\right]$

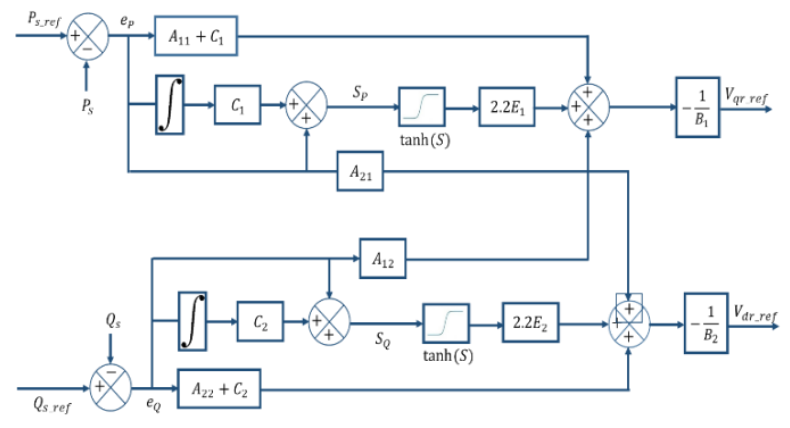

Fig. 5. SMC Structure

5) Stability analysis: The convergence condition of power sliding surfaces is verified using Lyapunov stability criteria:

$S(X) . \dot{S}(X)<0$

Replacing (31) to (36) into (37):

$\left\{\begin{array}{l}\varepsilon_{1}>\left|E_{1}\right| \\ \varepsilon_{2}>\left|E_{2}\right|\end{array}\right.$

So it can be seen from the above analysis that the minimum switching gain which guarantees the stability of the controlled system, only depends on the load disturbances and parameter variations. However, if the switching gains are greater, the sliding surface can be reached by the system states more quickly, but that may intensify the chattering phenomenon, while the smaller one alleviates the chattering problem but the dynamic response becomes slower. Thus, the optimal sliding coefficients chosen in this paper are expressed by (39) in order to weigh out between the settling time and the chattering problem.

$\left\{\begin{array}{l}\varepsilon_{1}=2.2\left|E_{1}\right| \\ \varepsilon_{2}=2.2\left|E_{2}\right|\end{array}\right.$

\section{RESULTS AND DISCUSSION}

To verify that the wind system works properly under the ASMC strategy, two simulation tests are performed using MATLAB/SIMULINK environment for 10s simulation time. The parameters listed in Table 1 are loaded into system model that is based on 2MW DFIG. In the first test, a comparative study between the field oriented control with classical PI controllers and the ASMC was conducted in order to assess the effectiveness and robustness of this techniques against DFIG parameter variations (rotor resistance $\mathrm{Rr}$, stator inductance Ls and rotor inductance Lr). In this test, the mechanical part and the MPPT blocks are removed from the model. Only the DFIG and its control are required. The controllers are directly supplied by a step change of active power at $\mathrm{t}=5 \mathrm{~s}$. The second test was carried out adopting the complete system model under variable wind speed. The stator reactive power reference is kept constant at zero for all these simulation tests in order to assure the unity power factor. Then the obtained results from the MPPT technique and the mechanical and the electrical magnitudes are analyzed to derive the respective conclusions.

TABLE I. WIND TURBINE PARAMETERS

\begin{tabular}{|c|c|c|}
\hline Parameter & Symbol & Value/Unit \\
\hline Turbine rated power & $P_{n}$ & $2 \mathrm{MW}$ \\
\hline Air density & $\rho$ & $1.225 \mathrm{Kg} / \mathrm{m}^{3}$ \\
\hline Sweap area radius & $\mathrm{R}_{\mathrm{t}}$ & $45 \mathrm{~m}$ \\
\hline System inertia & $\mathrm{J}$ & $100 \mathrm{Kg} \cdot \mathrm{m}^{2}$ \\
\hline Gearbox ratio & $\mathrm{G}$ & 90 \\
\hline Viscous friction & $\overline{f_{v}}$ & 0.00673 N.m.s/rad \\
\hline poles pairs number & $\overline{\mathrm{p}}$ & 2 \\
\hline Line-to-line grid voltage & $\mathrm{V}_{\mathrm{LL} \_ \text {rms }}$ & $690 \mathrm{~V}$ \\
\hline Stator rated current & $\mathrm{I}_{\mathrm{s}_{\mathrm{r}} \mathrm{ms}}$ & $1760 \mathrm{~A}$ \\
\hline Grid frequency & $\mathrm{f}$ & $50 \mathrm{~Hz}$ \\
\hline Stator resistance & $\mathrm{R}_{\mathrm{s}}$ & $29 \mathrm{~m} \Omega$ \\
\hline Stator inductance & $\mathrm{L}_{\mathrm{s}}$ & $2.6 \mathrm{mH}$ \\
\hline Mutual inductance & $\bar{M}$ & $2.5 \mathrm{mH}$ \\
\hline Rotor resistance & $\mathrm{R}_{\mathrm{r}}$ & $22 \mathrm{~m} \Omega$ \\
\hline Rotor inductance & $\mathrm{L}_{\mathrm{r}}$ & $2.6 \mathrm{mH}$ \\
\hline DC link voltage & $\mathrm{V}_{\mathrm{D}}$ & $1000 \mathrm{~V}$ \\
\hline
\end{tabular}

In the first test, which is the robustness test of the controller, the performance of ASMC was evaluated under parameter variations and compared with this of FOC with classical PI controller. The PI controller coefficients depend mainly on Ls, $\mathrm{Lr}$ and $\mathrm{Rr}$. Thus, those parameters are assumed to be raised by $20 \%$ and $50 \%$ from their original values.

Fig. 6 and 7 illustrate the active power response under Rr uncertainties. It is apparent that the active power follows reasonably well it reference with the two types of controllers that is clearly confirmed by a zero value of the power error in steady state. Zooming in the transient states, the ASMC keep a better settling time than FOC strategy for the different values of $\mathrm{Rr}$. This time was improved by SMC from $46 \mathrm{~ms}$ to $35 \mathrm{~ms}$ under $+50 \%$ change of $\mathrm{Rr}$ with no overshoot. Nevertheless, it became bigger from $60 \mathrm{~ms}$ to $120 \mathrm{~ms}$ under the same change of $\mathrm{Rr}$ with an overshoot of $6.36 \%$. The performances of controllers under Ls variations are depicted in Fig. 8 and 9. Here too, with ASMC, the estimated power track well its reference with negligible steady state error under $20 \%$ and $50 \%$ change of Ls and the settling time was increased a bit from $46 \mathrm{~ms}$ to $57 \mathrm{~ms}$ for $1.5 \mathrm{Ls}$ change with an no overshoot and a static state error equal to zero. However, using the PI controller raise notably the settling time from $60 \mathrm{~ms}$ to $110 \mathrm{~ms}$ with an overshoot of $3.26 \%$. As it is seen also in the zoom of this figure, the estimated power struggle to achieve its reference with a static error of $-0.56 \%$. The effect of the $\mathrm{Lr}$ variations is illustrated in Fig. 10 and 11. It can be seen that the ASMC has better and faster transient response than the PI controller based FOC. The settling time was reduced drastically from $46 \mathrm{~ms}$ to $5 \mathrm{~ms}$ without overshoot by adopting the first controller but, using the second one, it was multiplied from $60 \mathrm{~ms}$ to $110 \mathrm{~ms}$ with an overshoot of $3.25 \%$ and the static 
error can reach $2.59 \%$. As a result, it can be observed that the ASMC is more robust than the classical FOC and still yield consistent results even if machine parameters have varied.

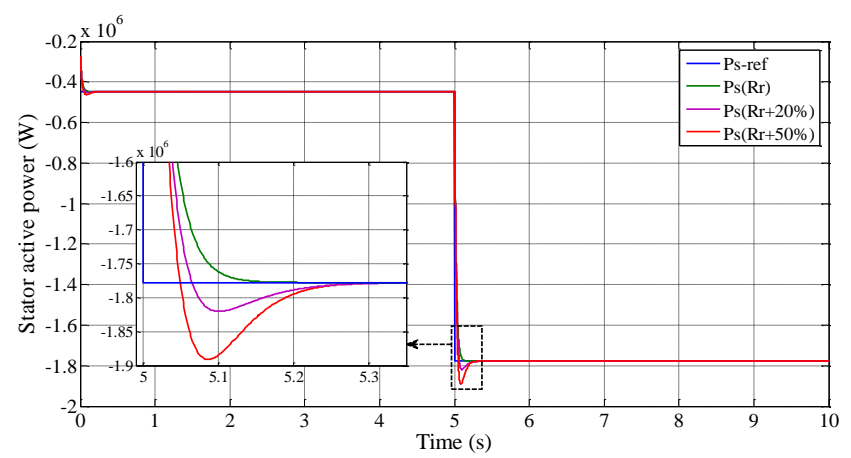

Fig. 6. PI Controller Robustness under $\mathrm{R}_{\mathrm{r}}$ Variations.

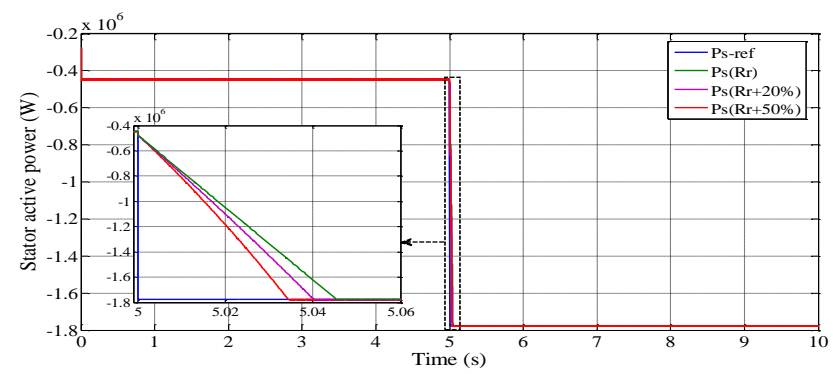

Fig. 7. Sliding Mode Controller Robustness under $\mathrm{R}_{\mathrm{r}}$ Variations.

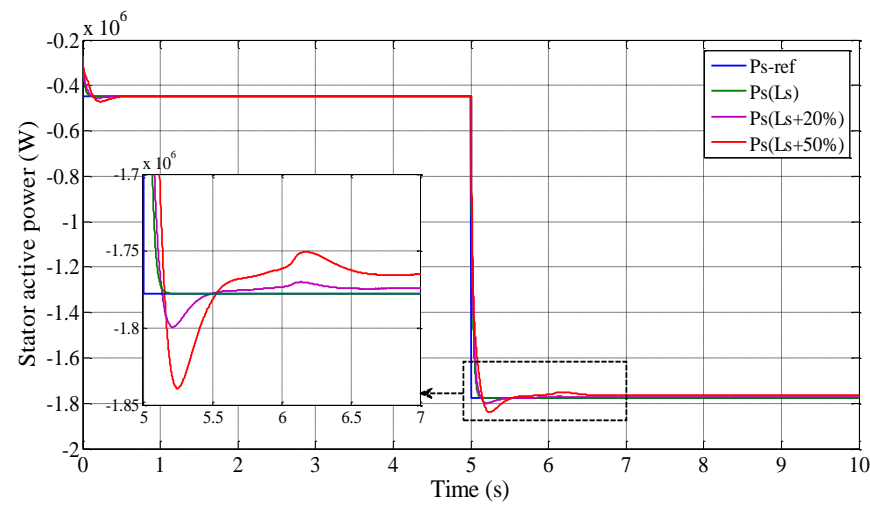

Fig. 8. PI Controller Robustness under $\mathrm{L}_{\mathrm{s}}$ Variations.

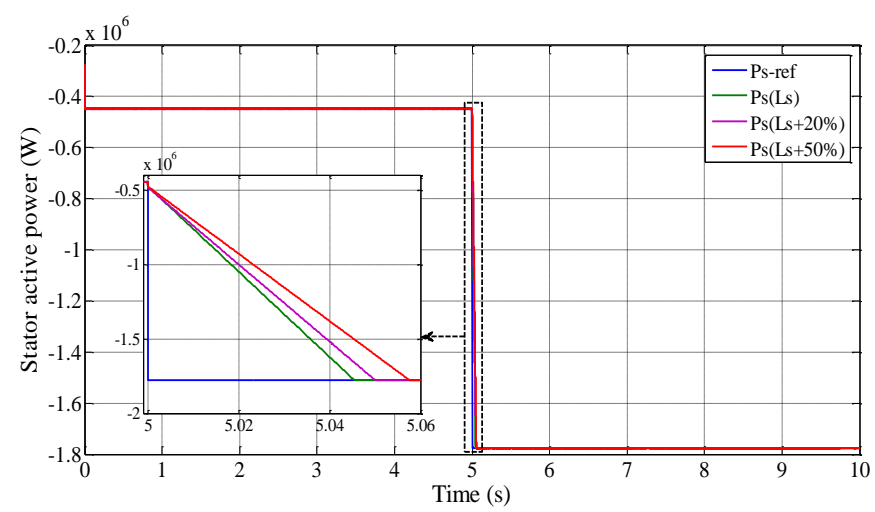

Fig. 9. Sliding Mode Controller Robustness under $\mathrm{L}_{\mathrm{s}}$ Variations.

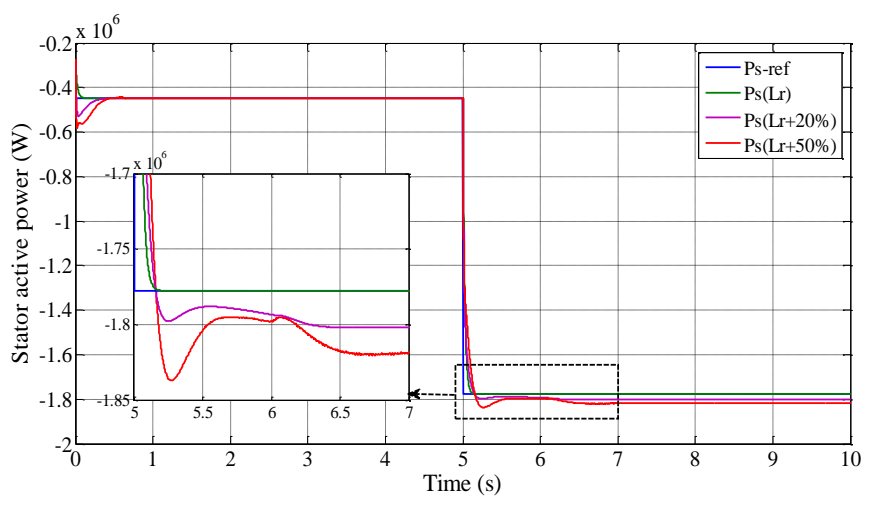

Fig. 10. PI Controller Robustness under $\mathrm{L}_{\mathrm{r}}$ Variations.

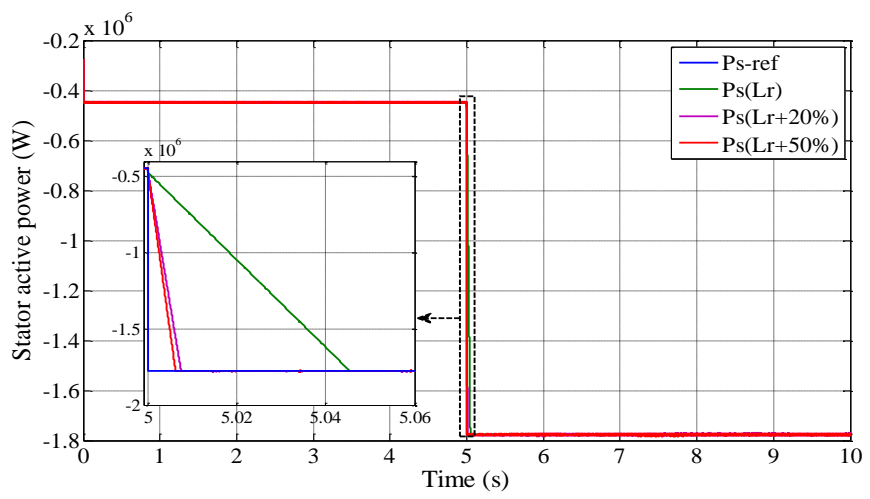

Fig. 11. Sliding Mode Controller Robustness under $\mathrm{L}_{\mathrm{r}}$ Variations.

In the second test, the wind turbine model as a whole was put to the simulation. This model is fed by a variable wind speed that changes in the range of $5 \mathrm{~m} / \mathrm{s}$ to $11 \mathrm{~m} / \mathrm{s}$ with an average of $8 \mathrm{~m} / \mathrm{s}$ as shown in Fig. 12 making the wind system operates at maximum wind power extraction region. A turbulence intensity of $5 \%$ was introduced to give a faithful image to the wind speed profile.

Under these wind variations, the angular velocity of electrical machine evolves as depicted in Fig. 13. It can be observed that the machine speed dynamic is slower than wind speed one and the oscillations are damped due to the turbine inertia. A reduced inertia is considered in this model in order to simulate the model in a rational amount of time. Note that the real $2 \mathrm{MW}$ wind turbine can have an inertia ten times greater than the used one.

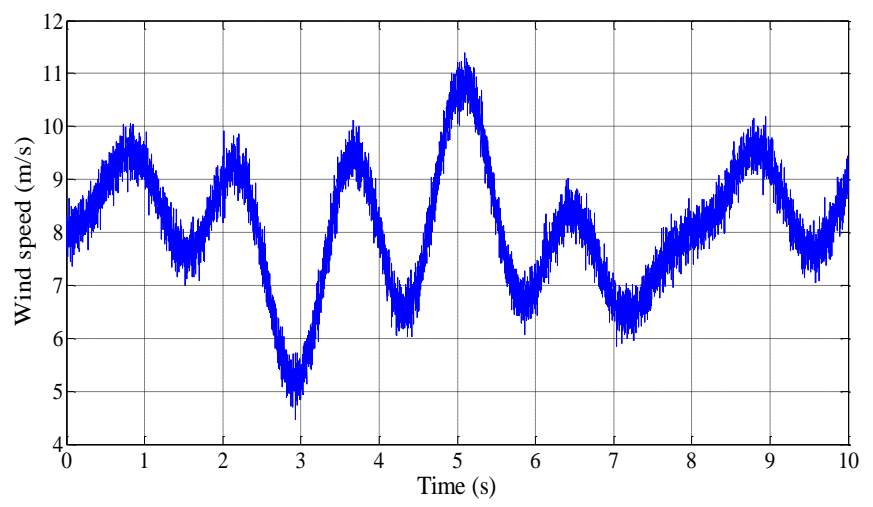

Fig. 12. Variable Profile of Wind Speed. 


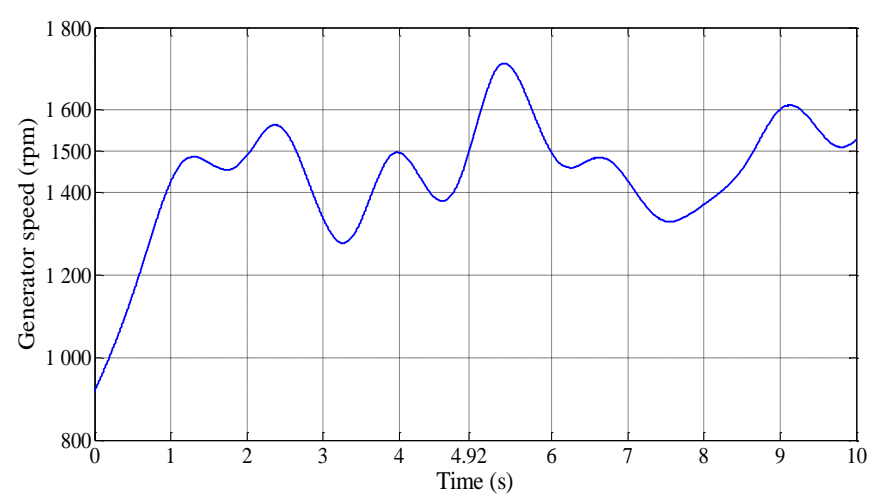

Fig. 13. Mechanical Speed of DFIG Shaft.

The acquired performance from the MPPT strategy is represented in Fig. 14. It is clear that the OPC technique cannot maintain the $C_{p}$ at its maximal value 0.48 all the simulation time. When the wind speed change rapidly, $C_{p}$ drops significantly from 0.48 to $0.38, \mathrm{C}_{\mathrm{p}}$ does not exceed 0.45 under medium variations and under small fluctuations, the value of $C_{p}$ is kept close to its optimal value. This behavior was expected because this technique is based on hypothesis that the wind speed variations are considered null in steady operation mode.

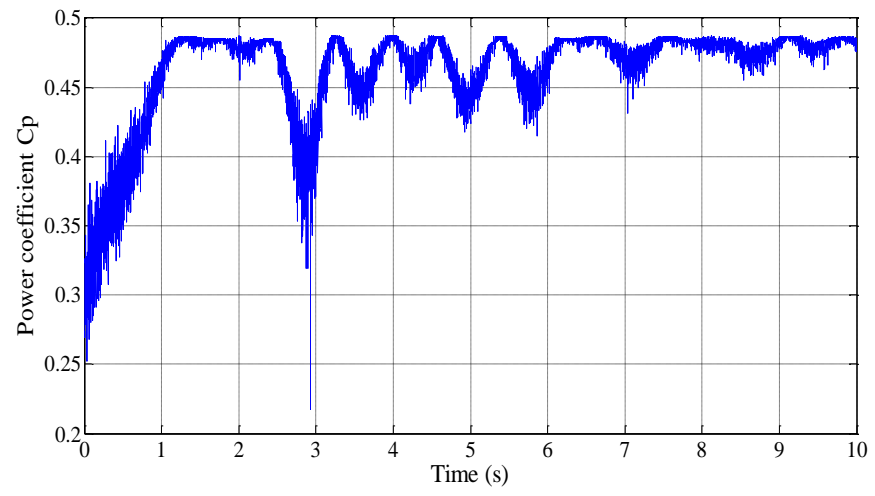

Fig. 14. Ppower Coefficient Cp using OP-MPPT.

The power balance in the generator is shown in Fig. 15. It should be noticed that the copper losses in stator and rotor are not represented because they are negligible in comparison with generated powers. It is observed that the direction of the rotor power was changed through synchronous velocity. It is positive in the subsynchronous region indicating that it is absorbed by the rotor machine. When the speed intersect with synchronous, the rotor power drops to zero and then changes the sign in supersynchronous mode which means that the rotor generates it. The stator power is negative throughout the simulation time, which indicates that the machine injects the power into the grid through its stator. By neglecting the losses copper, the net power is close to the turbine mechanical power and it can exceed the stator power, which means that the turbine can split the generated power between the two DFIG members. In the same figure, the stator power reference generated by the MPPT strategy is also depicted. It is clear that the estimated stator power track its reference with a satisfactory accuracy, which proves the good performances of the SMC under variable wind conditions.

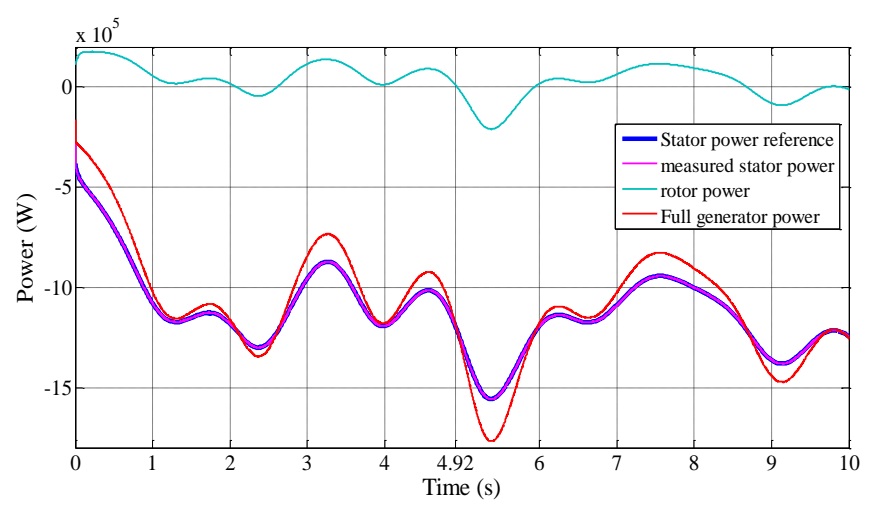

Fig. 15. Power Balance and Tracking Response of Stator Active Power.

Fig. 16 shows the stator reactive power control. In order to maintain the unit power factor, the reactive power reference was set to zero. Its measured value fluctuates around 0 in a variation range of 120 VAR. In addition, it is clear that this power is not affected by stator active power variations meaning that the sliding controllers of stator active and reactive powers are completely decoupled. This result is also confirmed by stator voltage and current curves of a phase depicted in Fig. 17. The two curves are in phase opposition, indicating that the stator machine generates a pure active power. Furthermore, the variations of stator power translate to variations in the stator current waveform.

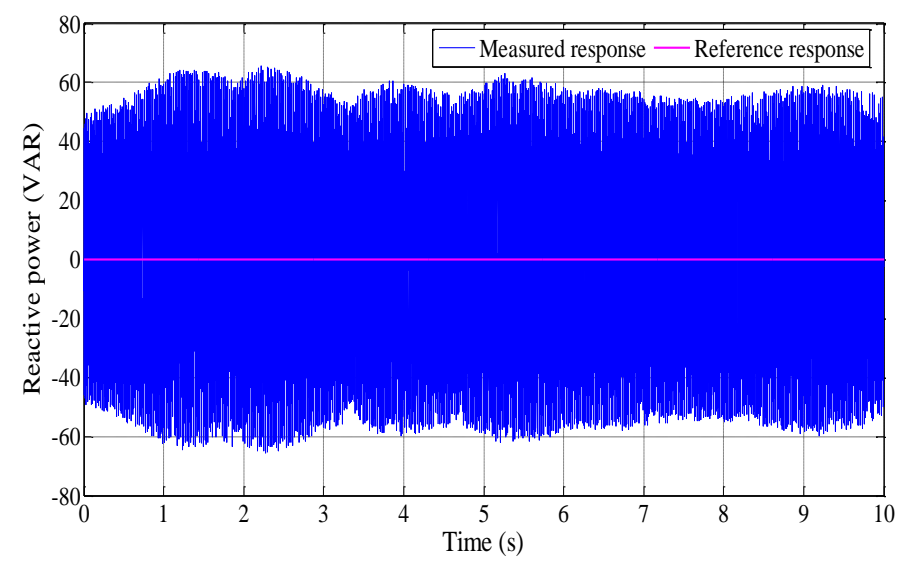

Fig. 16. Tracking Response of Stator Reactive Power.

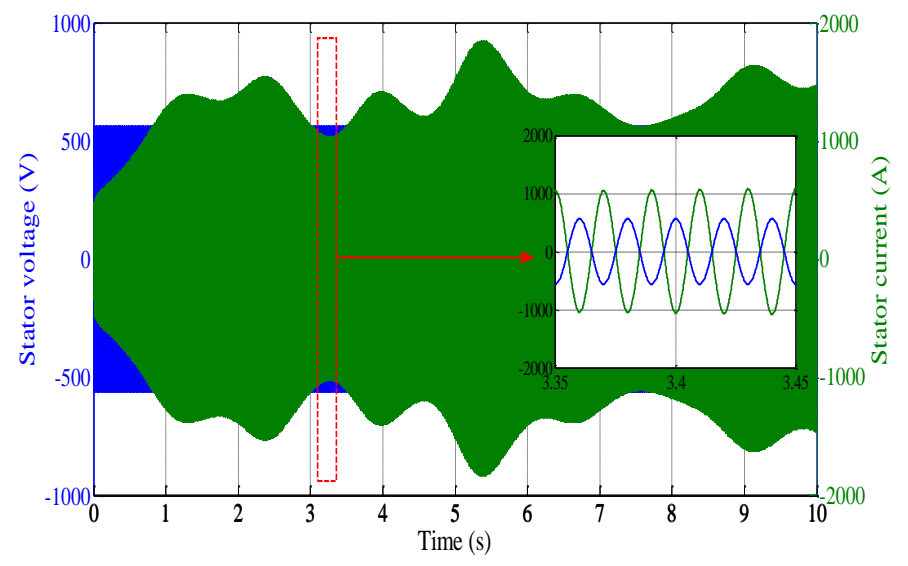

Fig. 17. Stator Current Vs Stator Voltage Waveform. 


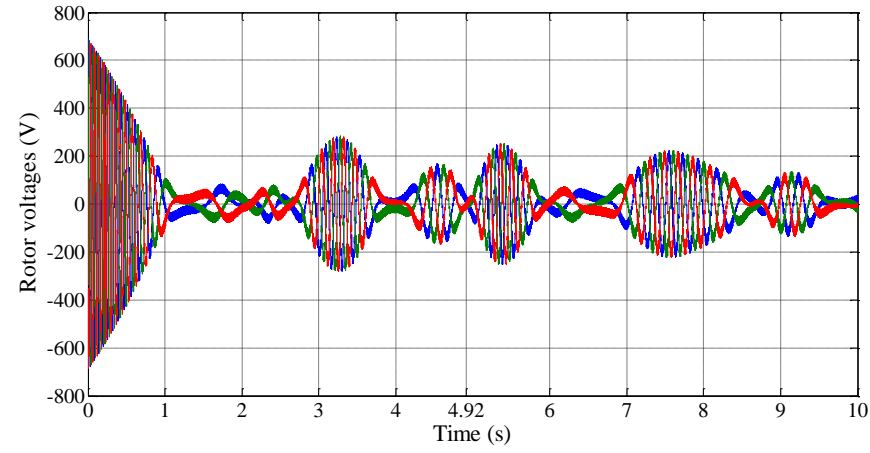

Fig. 18. Three Phase Rotor Voltages.

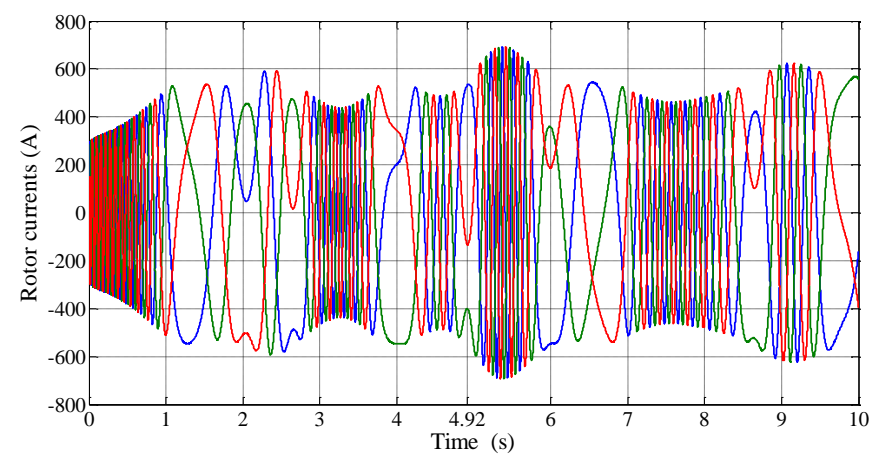

Fig. 19. Three Phase Rotor Currents.

Fig. 18 and 19 show the three phase rotor voltages and rotor currents respectively. For both magnitudes, the frequency decrease around the synchronous velocity and the magnitude sequence changes from $a, b, c$ to $a, c, b$ when the operation mode switch from subsynchronous to supersynchronous and vice versa. Furthermore, it can be noticed that the rotor voltage trends to zero when the generator velocity cross synchronous as expected by the fact that the slip is proportional to the rotor voltage.

\section{CONCLUSION}

The present paper proposes a robust adaptive sliding mode controller to enhance the power quality harvested by a wind turbine based on DFIG. The ASMC is adopted to improve the electrical generator performances and the OP-MPPT strategy was applied to keep the power coefficient of the system at its maximum. After modeling and testing the 2MW wind system using MATLAB/SIMULINK environment under different operating conditions, the main finding of this work are:

- The OP-MPPT assured a good tracking of the optimal wind power in medium and low wind speed variations but it had shown a poor capability to deal with the high variations of wind speed.
- The proposed strategy had superior performances to deal with the machine parameters variations and external disturbances than the FOC based on PI controllers. Using this last one, High overshoot appears and the steady state error increases significantly with the machine parameters changes. On the other side, the measured powers in the sliding mode control follow well their references with no overshoot, fast transient response and a steady state error equal to zero in same operating conditions.

\section{REFERENCES}

[1] Allouhi, A., Zamzoum, O., Islam, M. R., Saidur, R., Kousksou, T., Jamil, A., \& Derouich, A. (2017). Evaluation of wind energy potential in Morocco's coastal regions. Renewable and Sustainable Energy Reviews, 72, 311-324.

[2] Civelek, Z., Lüy, M., Çam, E., \& Mamur, H. (2017). A new fuzzy logic proportional controller approach applied to individual pitch angle for wind turbine load mitigation. Renewable Energy, 111, 708-717.

[3] Hossain, M. M., \& Ali, M. H. (2015). Future research directions for the wind turbine generator system. Renewable and Sustainable energy reviews, 49, 481-489.

[4] Global Wind Energy Council (GWEC), Global Wind Statistics 2017. 〈http://www.gwec.net/〉 [accessed 03.05.2018].

[5] Kesraoui, M., Chaib, A., Meziane, A., \& Boulezaz, A. (2014). Using a DFIG based wind turbine for grid current harmonics filtering. Energy conversion and management, 78, 968-975.

[6] Lin, W. M., Hong, C. M., \& Cheng, F. S. (2011). Design of intelligent controllers for wind generation system with sensorless maximum wind energy control. Energy Conversion and Management, 52(2), 1086-1096.

[7] Bedoud, K., Ali-rachedi, M., Bahi, T., \& Lakel, R. (2015). Adaptive fuzzy gain scheduling of PI controller for control of the wind energy conversion systems. Energy Procedia, 74, 211-225.

[8] European Commission's science and knowledge service, Joint Research Centre (JRC) Annual Report 2016. 〈http:// ec.europa.eu/〉 [accessed 03.05.2018].

[9] Varzaneh, S. G., Gharehpetian, G. B., \& Abedi, M. (2014). Output power smoothing of variable speed wind farms using rotor-inertia. Electric Power Systems Research, 116, 208-217.

[10] Salleh, Z., Sulaiman, M., Omar, R., \& Patakor, F. A. (2016, September). Optimization of fuzzy logic based for vector control induction motor drives. In Computer Science and Electronic Engineering (CEEC), 2016 8th (pp. 83-88). IEEE.

[11] Zamanifar, M., Fani, B., Golshan, M. E. H., \& Karshenas, H. R. (2014). Dynamic modeling and optimal control of DFIG wind energy systems using DFT and NSGA-II. Electric Power Systems Research, 108, 50-58.

[12] Zin, A. A. B. M., HA, M. P., Khairuddin, A. B., Jahanshaloo, L., \& Shariati, O. (2013). An overview on doubly fed induction generators' controls and contributions to wind based electricity generation. Renewable and Sustainable Energy Reviews, 27, 692-708.

[13] Jadhav, H. T., \& Roy, R. (2013). A comprehensive review on the grid integration of doubly fed induction generator. International Journal of Electrical Power \& Energy Systems, 49, 8-18.

[14] Ouassaid, M., Elyaalaoui, K., \& Cherkaoui, M. (2016). Sliding Mode Control of Induction Generator Wind Turbine Connected to the Grid. In Advances and Applications in Nonlinear Control Systems (pp. 531-553). Springer, Cham. 
[15] Feng, Y., Zhou, M., Han, F., \& Yu, X. (2018). Speed Control of Induction Motor Servo Drives Using Terminal Sliding-Mode Controller. In Advances in Variable Structure Systems and Sliding Mode ControlTheory and Applications (pp. 341-356). Springer, Cham.

[16] Taleb, M., \& Cherkaoui, M. (2016, November). Active and Reactive Power Robust Control of Doubly Fed Induction Generator Wind Turbine to Satisfy New Grid Codes. In International Afro-European Conference for Industrial Advancement (pp. 106-118). Springer, Cham.

[17] Morshed, M. J., \& Fekih, A. (2017, May). Design of a second order Sliding Mode approach for DFIG-based wind energy systems. In American Control Conference (ACC), 2017 (pp. 729-734). IEEE.

[18] Salem, F. B., \& Derbel, N. (2017). DTC-SVM-Based Sliding Mode Controllers with Load Torque Estimators for Induction Motor Drives. In Applications of Sliding Mode Control (pp. 269-297). Springer, Singapore.

[19] Abdullah, M. A., Yatim, A. H. M., Tan, C. W., \& Saidur, R. (2012). A review of maximum power point tracking algorithms for wind energy systems. Renewable and sustainable energy reviews, 16(5), 3220-3227.

[20] Mehdipour, C., Hajizadeh, A., \& Mehdipour, I. (2016). Dynamic modeling and control of DFIG-based wind turbines under balanced network conditions. International Journal of Electrical Power \& Energy Systems, 83, 560-569.

[21] Djoudi, A., Bacha, S., Chekireb, H., Berkouk, E. M., Benbouzid, M. E. H., \& Sandraz, J. (2017). Robust stator currents sensorless control of stator powers for wind generator based on DFIG and matrix converter. Electrical Engineering, 99(3), 1043-1051.

[22] Zamzoum, O., El Mourabit, Y., Errouha, M., Derouich, A., \& El Ghzizal, A. (2018). Power control of variable speed wind turbine based on doubly fed induction generator using indirect field-oriented control with fuzzy logic controllers for performance optimization. Energy Science \& Engineering.

[23] Bossoufi, B., Karim, M., Lagrioui, A., Taoussi, M., \& Derouich, A. (2015). Observer backstepping control of DFIG-Generators for wind turbines variable-speed: FPGA-based implementation. Renewable Energy, 81, 903-917.

[24] El Ouanjli, N., Taoussi, M., Derouich, A., Chebabhi, A., El Ghzizal, A., \& Bossoufi, B. (2018). High Performance Direct Torque Control of
Doubly Fed Induction Motor using Fuzzy Logic. Gazi University Journal of Science, 31(2).

[25] Ouanjli, N. E., Derouich, A., El Ghzizal, A., El Mourabit, Y., \& Taoussi, M. (2017). Contribution to the Improvement of the Performances of Doubly Fed Induction Machine Functioning in Motor Mode By the DTC Control. International Journal of Power Electronics and Drive Systems (IJPEDS), 8(3), 1117-1127.

[26] Taraft, S., Rekioua, D., Aouzellag, D., \& Bacha, S. (2015). A proposed strategy for power optimization of a wind energy conversion system connected to the grid. Energy Conversion and Management, 101, 489502 .

[27] Kairous, D., \& Wamkeue, R. (2012). DFIG-based fuzzy sliding-mode control of WECS with a flywheel energy storage. Electric Power Systems Research, 93, 16-23.

[28] Boumassata, A., \& Kerdoun, D. (2015, May). Direct powers control of DFIG through direct converter and sliding mode control for WECS. In Control, Engineering \& Information Technology (CEIT), 2015 3rd International Conference on (pp. 1-5). IEEE.

[29] Bekakra, Y., \& Attous, D. B. (2014). DFIG sliding mode control fed by back-to-back PWM converter with DC-link voltage control for variable speed wind turbine. Frontiers in Energy, 8(3), 345-354.

[30] Shehata, E. G. (2015). Sliding mode direct power control of RSC for DFIGs driven by variable speed wind turbines. Alexandria Engineering Journal, 54(4), 1067-1075.

[31] Saad, N. H., Sattar, A. A., \& Mansour, A. E. A. M. (2015). Low voltage ride through of doubly-fed induction generator connected to the grid using sliding mode control strategy. Renewable Energy, 80, 583-594.

[32] Shehata, E. G. (2017). A comparative study of current control schemes for a direct-driven PMSG wind energy generation system. Electric Power Systems Research, 143, 197-205.

[33] Barambones, O. (2010). Robust sliding mode control for a wind turbine system. IFAC Proceedings Volumes, 43(1), 7-12.

[34] Liu, Y., Wang, Z., Xiong, L., Wang, J., Jiang, X., Bai, G., ... \& Liu, S. (2018). DFIG wind turbine sliding mode control with exponential reaching law under variable wind speed. International Journal of Electrical Power \& Energy Systems, 96, 253-260. 